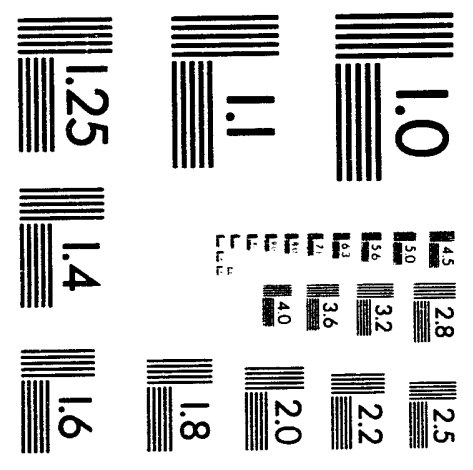



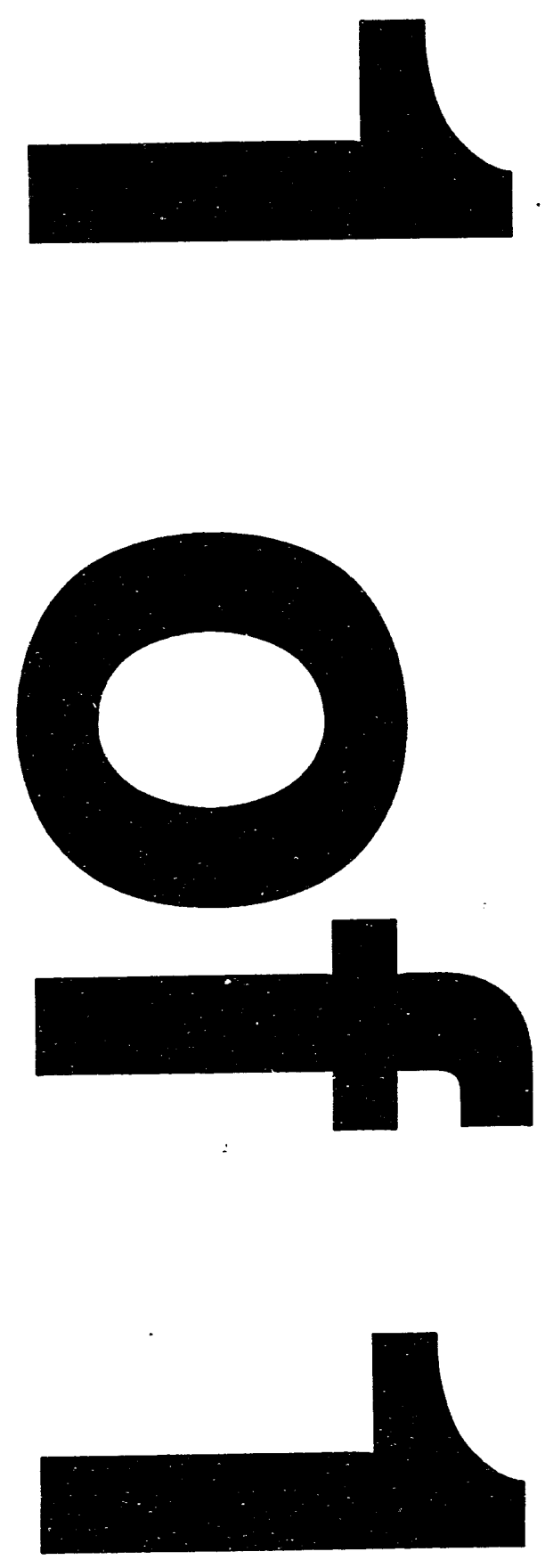


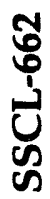

SSCL-662

February 1994

Distribution Category: 400

A. Drozhdin

N. Mokhov

R. Schailey

\section{HEB Beam Collimation System}

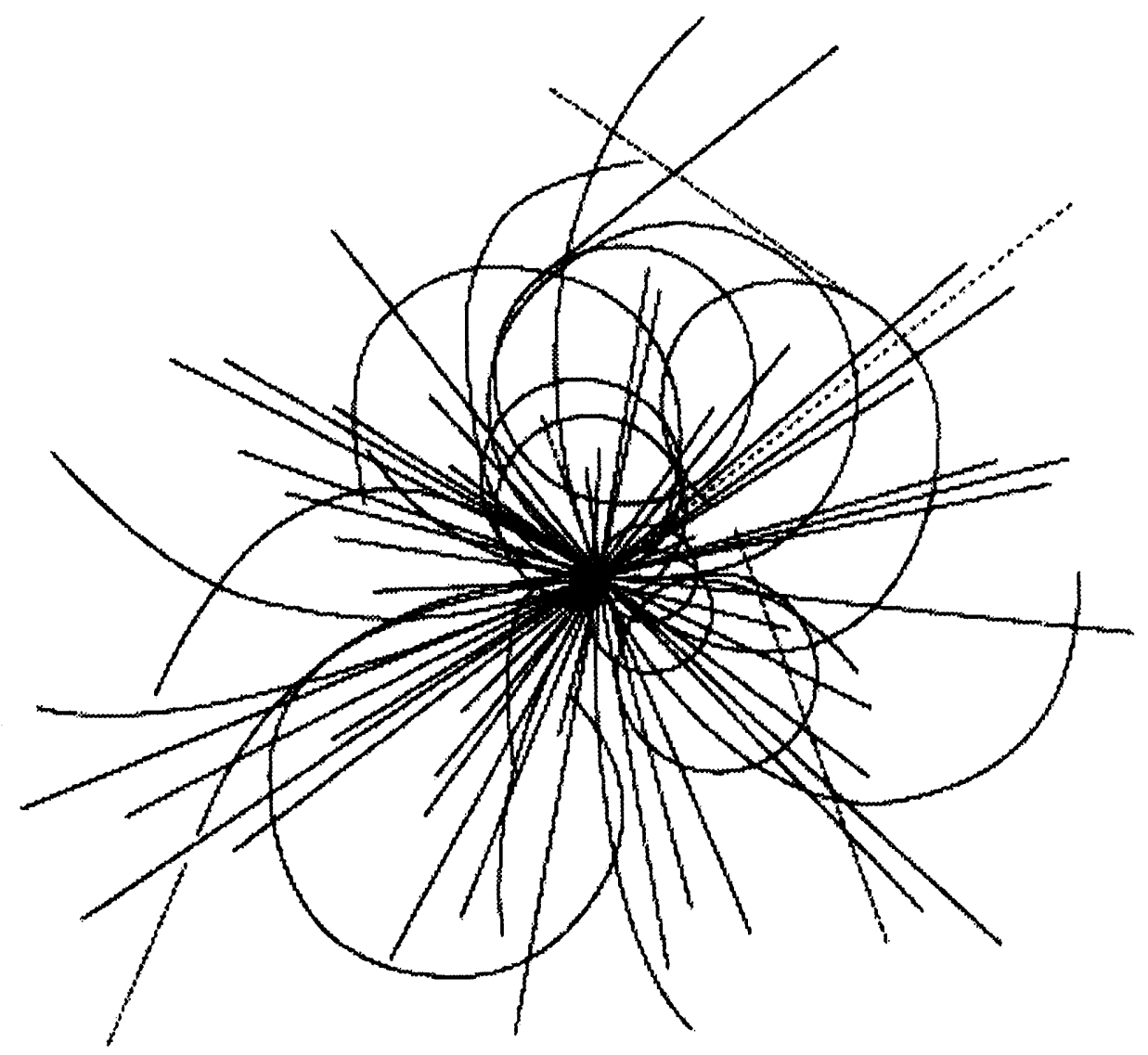

\section{Superconducting Super Collider Laboratory}




\section{Disclaimer Notice}

This report was prepared as an account of work sponsored by an agency of the United States Govemment. Nelther the United States Government or any agency thereof, nor any of their employees, makes any warranty, express or implied, of assumes any legal liability or responsibility for the accuracy, completeness, or usefulness of any intormation, apparatus, product, or process disclosed, or represents that the use would not infringe privately owned rights. Reference herein to any specific commercial product, process, or service by trade name, trademark, manufacturer, or otherwlse, does not necessarly consthute or imply its endorsement, recommendation, or tavoring by the United States Government or any agency thereof. The views and opinions of authors expressed herein do not necessarliy state or reflect those of the United States Government or any agency thereot. 


\title{
HEB Beam Collimation System
}

\author{
A. Drozhdin, N. Mokhov, and R. Schailey \\ Superconducting Super Collider Laboratory* \\ 2550 Beckleymeade Ave. \\ Dallas, TX 75237 USA
}

February 1994

*Operated by the Universities Research Association, Inc., for the U.S. Department of Energy under Contract No. DE-AC35-89ER40486. 


\title{
HEB Beam Collimation System
}

\author{
A. Drozhdin, N. Mokhov, and R. Schailey
}

\begin{abstract}
The detailed studies of aperture limitations, beam loss scenarios and energy deposition calculations have been performed to establish the requirements on a collimation system for the High Energy Booster (HEB), $2 \mathrm{TeV}$ superconducting injector for the Supercollider. Calculations of a source term and hadronic and electromagnetic cascades in the HEB components and shielding are done with MARS12 code, particle tracking through the lattice-with STRUCT code. A multicomponent beam collimation system is proposed to provide reliable operation of the HEB under any circumstances and a clean $2 \mathrm{TeV}$ beam injected into the Collider.
\end{abstract}




\subsection{INTRODUCTION}

In the Superconducting Super Collider (SSC) design a beam collimation in the High Energy Booster (HEB), $2 \mathrm{TeV}$ superconducting injector for the main Collider, was not included in the baseline document and cost estimate. But the need for scrapers and collimators for the HEB was recognized and the East long straight section, at $\mathrm{H} 50$, has been identified ${ }^{1}$ for a dogleg with resistive magnets. Since that time, a more detailed study of aperture limitations, beam loss scenarios and energy deposition calculations have been performed to establish the requirements on a collimation system for the HEB. Calculations of a source term and hadronic and electromagnetic cascades in the HEB components and shielding were done with MARS12 code, ${ }^{2}$ particle tracking through the lattice-with STRUCT. ${ }^{3}$

\subsection{BEAM LOSS IN HEB}

At the onset, one can expect that beam-induced radiation environment in the HEB is much better compared to the Collider. The impact of the same beam loss to the equipment in the HEB is about 10 times lower because of 10 times lower energy of the proton beam. In addition, the beam loss rate in the HEB is expected to be lower compared to the Collider because of the following reasons:

- lower beam-gas interaction rate due to reduced synchrotron radiation;

- no pp-collisions;

- admittance of the HEB is about 2 times larger compared to the Collider.

However, beam loss in the HEB can occur during Medium Energy Booster (MEB)-to-HEB injection $\left(10^{13}\right.$ protons at $0.2 \mathrm{TeV}$ ) and during acceleration (up to $1 \%$ of the full HEB beam). Loss of such a high intensity beam can cause a quench of superconducting magnets and hinder the Collider operation (availability) since it will take a much longer time to recover from a quench than the HEB cycle time. Aperture limitations in the HEB extraction and Collider injection Lambertson magnetic septa and downstream quadrupoles also require collimation of the HEB beam before its transfer into the Collider ring to avoid meltdown of septa, especially the HEB extraction septum. This may require removal of several percent of the HEB beam before transfer. Experience at the Tevatron ${ }^{4}$ shows that reliable operation of a superconducting machine, especially at beam extraction, is possible only if a set of collimators is incorporated in the ring lattice. According to the measurements made at the Tevatron, such a system must remove beam halo particles and reduce the intensity outside the $6 \sigma$ radius to a level lower than $10^{-5}$ of the HEB beam.

\subsection{SCRAPER/COLLIMATOR SYSTEM}

Horizontal and vertical scrapers (two for each direction) are required to remove beam halo particles and localize the beam loss in warm regions. Scraping of high intensity, high energy beam halo will cause a quench of the downstream superconducting magnets due to the secondaries and neutrals traveling downstream, if they are not directed away from the superconducting elements. Thus it is necessary to have a dogleg. The only space that can accommodate such a dogleg is the East utility long straight section, at H50. In addition to the dogleg, collimators are required to absorb the secondaries from the scrapers to protect the downstream superconducting magnets and to reduce the radiation dosage. ${ }^{5}$ The $\mathrm{H} 50$ region of HEB between quadrupole magnets Q5-Q5 is also convenient for the scrapers and collimators installation. The $\beta$-function is high enough ( $307 \mathrm{~m}$ in radial and $116 \mathrm{~m}$ in vertical planes (Figure 1 ) at scraper location to provide good deflection of the halo protons into the scraper surface. 


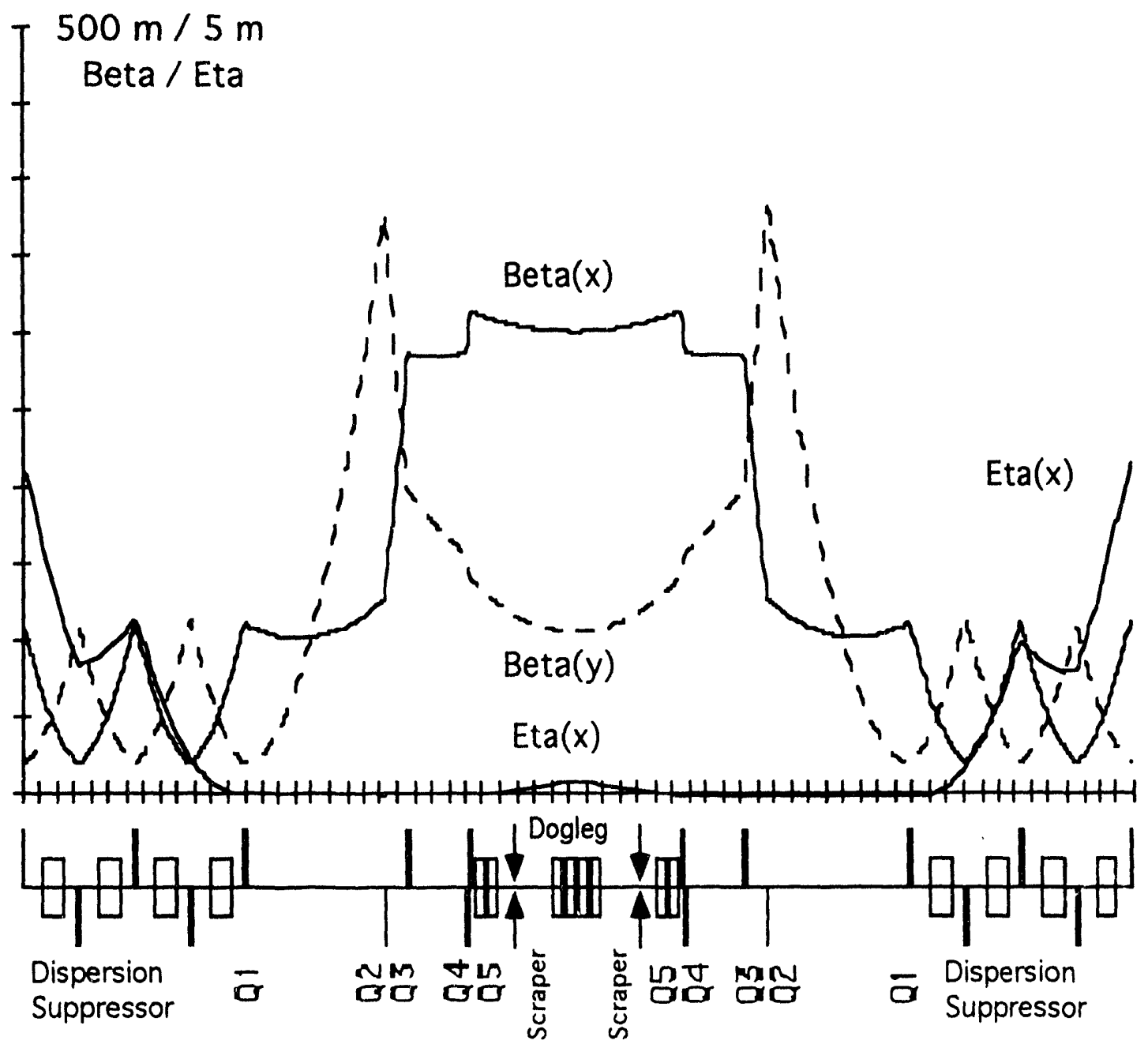

Figure 1. HEB East Long Straight Section (H50) Lattice Functions.

The beam collimation system consists of horizontal and vertical scrapers and a set of collimators (Figure 2). Scrapers have movable copper jaws 1.2-m long controlled by high precision motors. The jaws are surrounded by radiation shielding. A thick tungsten target, $0.5-\mathrm{mm}$ thick, is used to deflect halo particles deeper into the scraper front surface. The target-scraper offset is about $50 \mu \mathrm{m}$ relative to target.

The essential part of the beam collimation system is a horizontal dogleg structure, which provides a complete interception of neutral particles, and a very good $(>97 \%)$ interception of low-momentum $\left(\mathrm{p}<0.7 \mathrm{p}_{0}\right)$ charged particles out of the scrapers. Here, $\mathrm{p}_{0}$ is the circulating beam momentum. Eight, 6-m long 1-Tesla resistive dipoles used as bump-magnets perfectly fit in such a dogleg structure. The symmetrical structure shown in Figure 2 is used to clean the beam circulating in opposite directions.

All the equipment of the beam collimation system is similar to the equipment of the Collider beam collimation system. ${ }^{6}$ Collimator jaws $2.8-\mathrm{m}$ long are installed at $25 \sigma$ position from the circulating beam axis. The physical aperture (admittance) of the HEB at $2 \mathrm{TeV}$ is equal to $42 \sigma$ of circulating beam. Particle distribution at the front surface of the scraper at $2 \mathrm{TeV}$ is shown in Figure 3. The amount of protons with momentum $\mathrm{p}>0.7 \mathrm{p}_{0}$, going out of the scraper is equal to $5 \%$ from the scraped intensity. These protons contribute to long range beam loss in the HEB. 


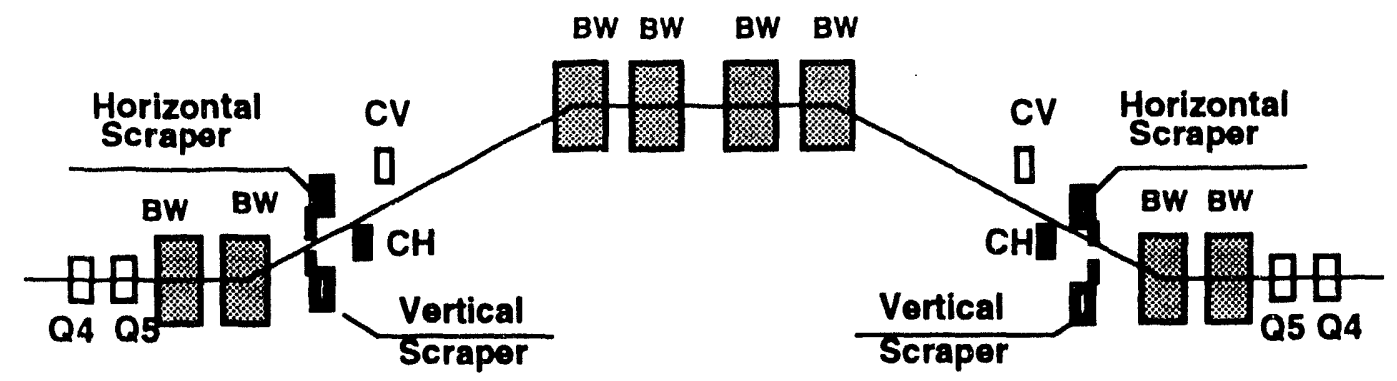

Figure 2. HEB Beam Collimation System Schematic View at H50 Region.
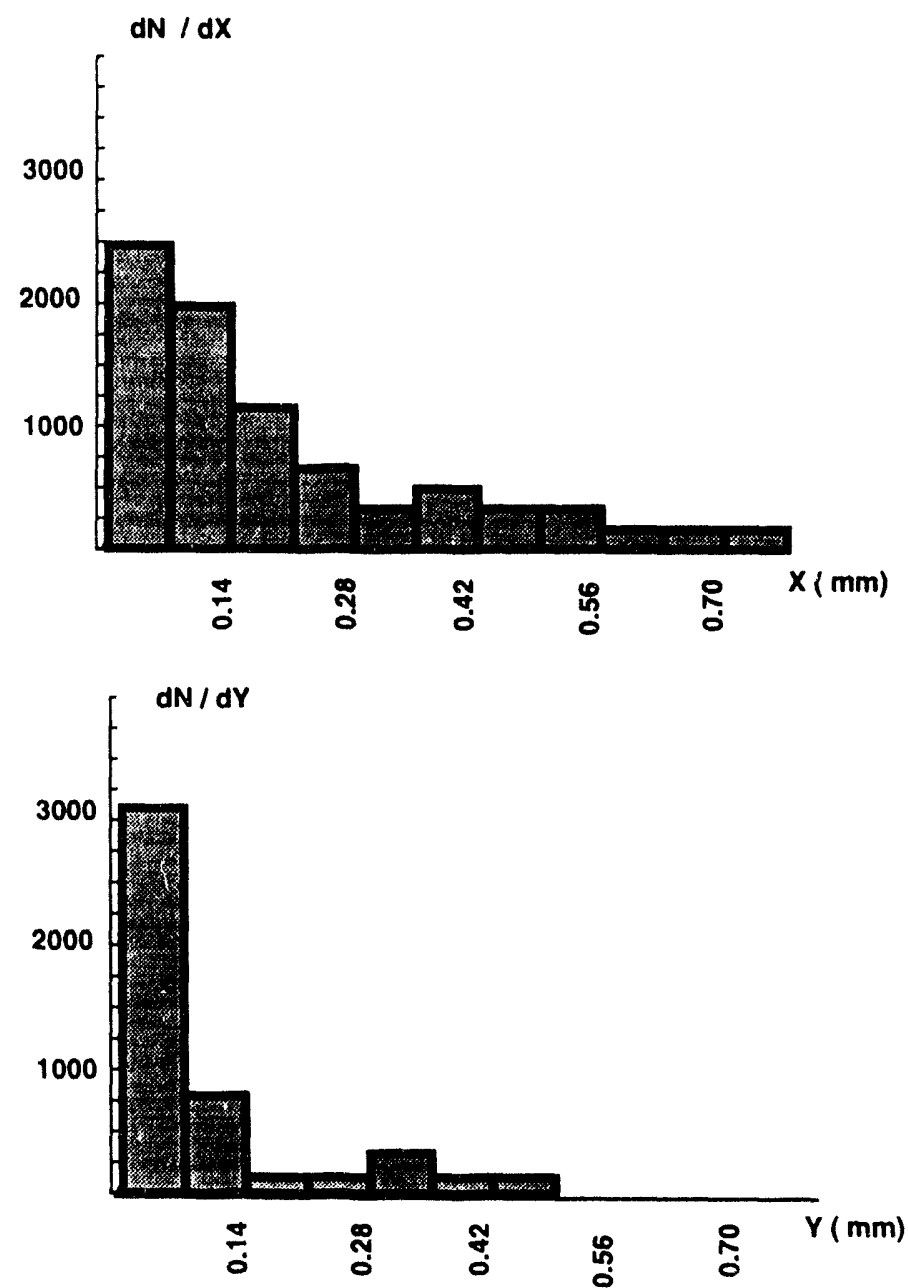

Figure 3. Horlzontal and Vertical $2 \mathrm{TeV}$ Proton Distribution at the Front Face of Scraper.

Beam loss during injection from MEB to HEB must be absorbed by collimators in the two short straight sections in the South: collimators in the Southwest, at H80, for clockwise injection and in the Southeast, at H60, for counterclockwise injection (Figure 4). The changes in the southeast and southwest short straight sections, and in the East long straight section are summarized in the Table 1. These changes have been included in the Level 3 Specification Document. ${ }^{1}$ All the collimators and scrapers are in the warm region. Note that the coil of each magnet immediately downstream of either a scraper or a collimator is protected from secondaries by putting shielding around the beam pipe upstream of the magnet. 


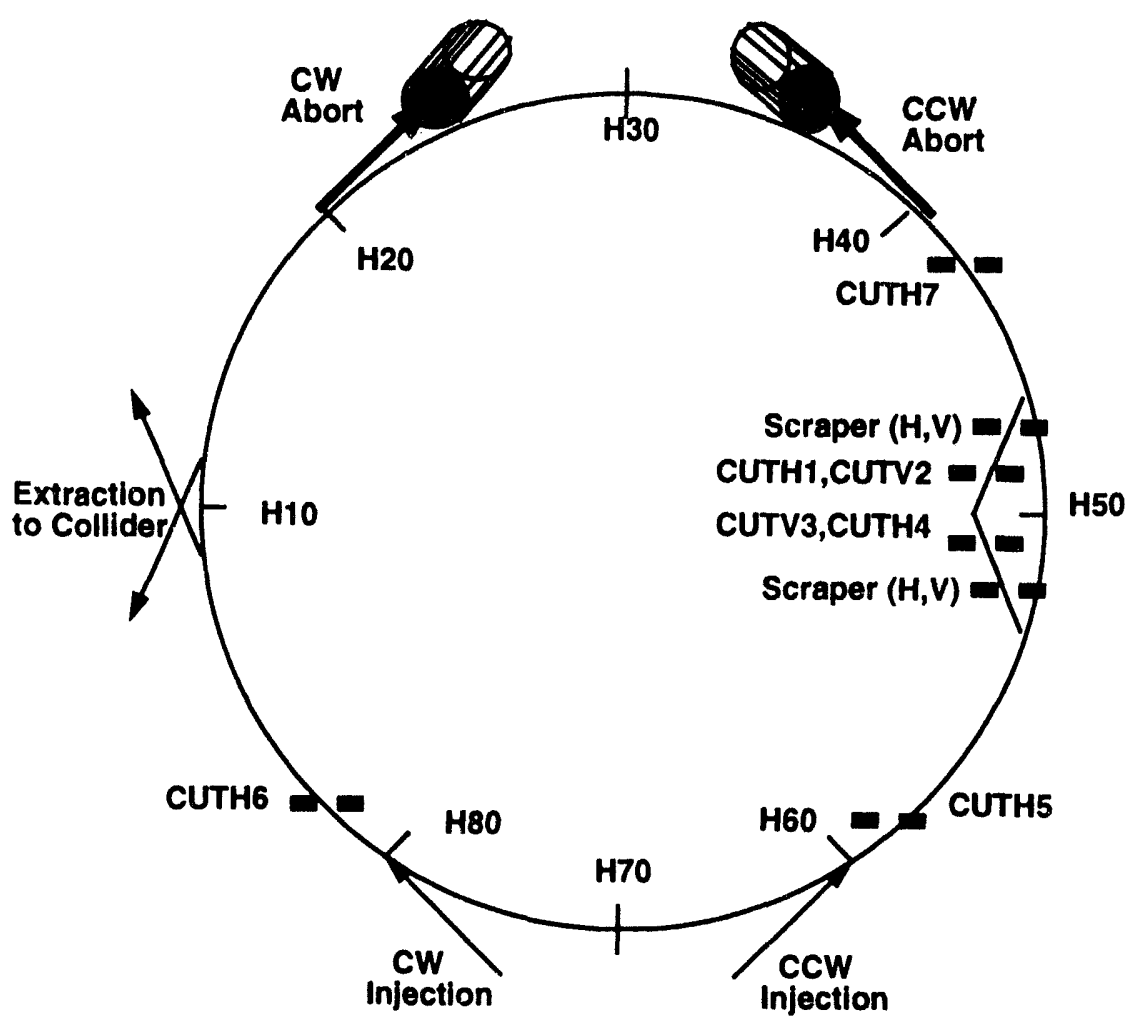

Figure 4. HEB Layout with Beam Collimation System.

Table 1. HEB Beam Collimation System Parameters.

\begin{tabular}{|c|c|c|c|c|}
\hline Section & No. of Jaws & $\begin{array}{l}\text { Collimation } \\
\text { Plane }\end{array}$ & Functlon & No. of Magnets \\
\hline SW stralght ( $\mathrm{HBO})$ & 2 & Horizontal & CW In]. Collimation & None \\
\hline SE stralght (H60) & 2 & Horizontal & CCW In]. Collimation & None \\
\hline E straight (H50) & $\begin{array}{l}1 \\
1 \\
1 \\
1 \\
1 \\
1 \\
1 \\
1 \\
\end{array}$ & $\begin{array}{l}\text { Horizontal } \\
\text { Vertical } \\
\text { Horizontal } \\
\text { Vertical } \\
\text { Horizontal } \\
\text { Vortical } \\
\text { Horizontal } \\
\text { Vertical } \\
\end{array}$ & $\begin{array}{l}\text { CW Horlz. Scraper } \\
\text { CW Vertlcal Scraper } \\
\text { CCW Horlz. Scraper } \\
\text { CCW Vertical Scraper } \\
\text { CW Collimation } \\
\text { CW Collimation } \\
\text { CCW Collimation } \\
\text { CCW Collimation } \\
\end{array}$ & 8 Dipoles \\
\hline NE straight (H40) & 1 & Horlzontal & CCW Collimation & None \\
\hline
\end{tabular}

Expected beam scraping rate at the HEB is $3 \times 10^{10}$ protons/s, that is 10 times larger compared to the Collider peak scraping rate. Taking into account the difference in the beam energy, one can assume the radiation conditions in the HEB and in the Collider are the same, so the design of scrapers and collimators in both machines should be the same. 


\subsection{ACCUMULATED DOSE AND QUENCH}

Dose accumulated in the HEB components over their lifetime (25 years) depends on the operational scenario. The Collider fill intensity is $2 \times 10^{13} \mathrm{ppp}$, with $8 \mathrm{HEB}$ cycles to fill one Collider ring. The number of Collider fills per year used for energy deposition and shielding estimates is 500 . With a possible upgrade of the Collider luminosity after the first 10 years of operation up to $10^{34}$, the HEB intensity is $1 \times 10^{14} \mathrm{ppp}$. In the case of fixed target operation of the HEB, a "test beam" intensity is supposed to be $2 \times 10^{13} \mathrm{ppp}$ for the first 10 years, and then $1 \times 10^{14} \mathrm{ppp}$, with 14 pulses per hour. One should assume the same scheduled number of hours per year as the Collider $(6000)$, with the design availability of the injector complex $85 \%$. Summarizing all the options, we arrive to four possible modes of the HEB operation with corresponding integrated number of protons in one direction:

- Collider Fill Mode: $L=10^{33}(1-25 \mathrm{yr})$

$2 \times 10^{13} \times 8 \times 500 \times 25=2 \times 10^{18}$

- Collider Fill Mode: $L=10^{33}(1-10 \mathrm{yr})+L=10^{34}(10-25 \mathrm{yr})$

$$
2 \times 10^{13} \times 8 \times 500 \times 10+1 \times 10^{14} \times 8 \times 500 \times 15=8 \times 10^{17}+6 \times 10^{18}=6.8 \times 10^{18}
$$

- Test Beam Mode: 14 pulses $/ \mathrm{hr}, 6000$ hours/yr, $85 \%$ availability

$$
2 \times 10^{13} \times 14 \times 6000 \times 0.85 \times 10+1 \times 10^{14} \times 14 \times 6000 \times 0.85 \times 15=1.2 \times 10^{20}
$$

- Mode 2+ Mode 3: $1.3 \times 10^{20}$

Without scrapers, the beam loss locations and rates are unpredictable. Estimates show that the accumulated over 25 year dose in the coils can range up to thousands Mrad. With the scrapers, for $2 \%$ scraping rate (design goal), corresponding total number of protons at scraper and calculated peak doses in "hot" components are given in Table 2. In a scenario that the HEB is used as an injector for the Collider, it fills Collider with beam eight times per Collider cycle. Figures 5 and 6 show the beam loss level due to scraping and the corresponding radiation dose for 25 years in the superconducting magnets. Calculated beam loss rate in quadrupole magnets Q3, Q4, Q5 is $2.5 \times 10^{6}$ protons-per-meter-per-second during the 30 second scraping procedure. The maximal dose accumulated in the inner coil of these magnets over 25 years of operation is $D=26 \mathrm{Mrad}$ (Table 2). Beam loss in magnets QF and B is $6 \times 10^{5}$ protons $/ \mathrm{m} / \mathrm{s}$. The accumulated peak dose over 25 years is $D=7 \mathrm{Mrad}$.

Table 2. Number of Protons at Scraper (2\%) and 25-year Dose in SC Quadrupoles.

\begin{tabular}{|c|c|c|c|c|}
\hline Mode & No. of Protons & $D_{1}$ (Mrad) & $D_{2}$ (Mrad) & $D_{3}$ (Mrad) \\
\hline 1 & $4.0 \times 10^{16}$ & 25.6 & 7.3 & 2.6 \\
\hline 2 & $1.4 \times 10^{17}$ & 89.6 & 25.6 & 9.0 \\
\hline 3 & $2.4 \times 10^{18}$ & 1536 & 439 & 154 \\
\hline 4 & $2.6 \times 10^{18}$ & 1664 & 475 & 166 \\
\hline
\end{tabular}

$D_{1}$ - Peak dose in Q3, Q4, Q5 quads with no collimators in $\mathrm{H} 40$ and $\mathrm{H} 60$

$\mathrm{D}_{2}$ - Peak dose in Q3, Q4, Q5 quads with collimators in $\mathrm{H} 40$ and $\mathrm{H} 60$

$\mathrm{D}_{3}$ - Peak dose in other quads and dipoles with no collimators in $\mathrm{H} 40$ and $\mathrm{H} 60$

In a scenario of the HEB Test Beam with a 4-minute cycle duration and intensity of the circulating bearn $2 \times 10^{13} \mathrm{ppp}$, the calculated beam loss rate in the quads Q3, Q4, Q5 is $1.5 \times 10^{8}$ protons $/ \mathrm{m} / \mathrm{s}$, and $3 \times 10^{7}$ protons $/ \mathrm{m} / \mathrm{s}$ in the magnets QF and B. The maximal accumulated dose over 25 years is equal to about 1500 Mrad. Besides these few magnets, scrapers enable the maximal radiation dosage for the purpose of material requirement of the magnets to be set at 100-200 Mrad over 25 years. 
An attempt to decrease the beam loss in quadrupoles Q3, Q4, Q5 by moving collimator jaws closer to the beam doesn't give a significant result. The beam loss in Q3 is decreased only two times. To eliminate the beam loss in quadrupoles Q3, Q4 and Q5, requires installation of two more collimators inside the 44-m long straight sections upstream and downstream of $\mathrm{H} 60$ region. That $44-\mathrm{m}$ region should be warm in this case. The beam loss distribution for this case is shown in Figures 7 and 8. The results are summarized in Table 2. Thus, the additional collimators in the $\mathrm{H} 40$ and $\mathrm{H} 60$ short straight sections would enable the radiation requirement to all the superconducting magnets to be set at $100 \mathrm{Mrad}$ over 25 years.

Instantaneous beam losses in the HEB should be limited by the level of a "fast" quench, $3 \times 10^{6}$ protons lost quasi-instantaneously $(<1 \mathrm{~ms})$ per meter at $2 \mathrm{TeV}$. One percent of the circulating beam intercepted by the scraper causes secondary particle beam loss in quadrupoles Q3, Q4 and Q5 at a level of $2 \times 10^{7}$ protons $/ \mathrm{m}$, that is six times higher of the fast quench level. Calculated particle loss at magnets $\mathrm{QF}$ and $\mathrm{B}$ coincides with the fast quench level. So, it is possible to allow instantaneous beam loss in the HEB scraper of not more than $0.1 \%$ of the circulating beam intensity. Calculated instantaneous temperature rise in the scraper jaws is about $100^{\circ} \mathrm{C}$ in this case.

Taking into account possible uncertainties in bean loss scenarios and in the overall model, one can conclude that dosage is unacceptably high in a few magnets, but not in the whole machine in the high intensity mode. Locations of the increased beam loss in the lattice, as shown in Figures 5-8, are very stable under different variations of the source term. Only the absolute value of the peaks is changed. The dosage in most of the magnets is about 20 times lower compared to that in the "hot" regions.

This allows us to suggest 100-Mrad dose as the design goal for cold mass material specification in the HEB magnets. About 10 magnets are defined as special ones with expected maximum dose in the excess of a few thousand Mrad over their lifetime, or with a possibility to replace them, if that is required, according to integrated BLM readings in those regions.

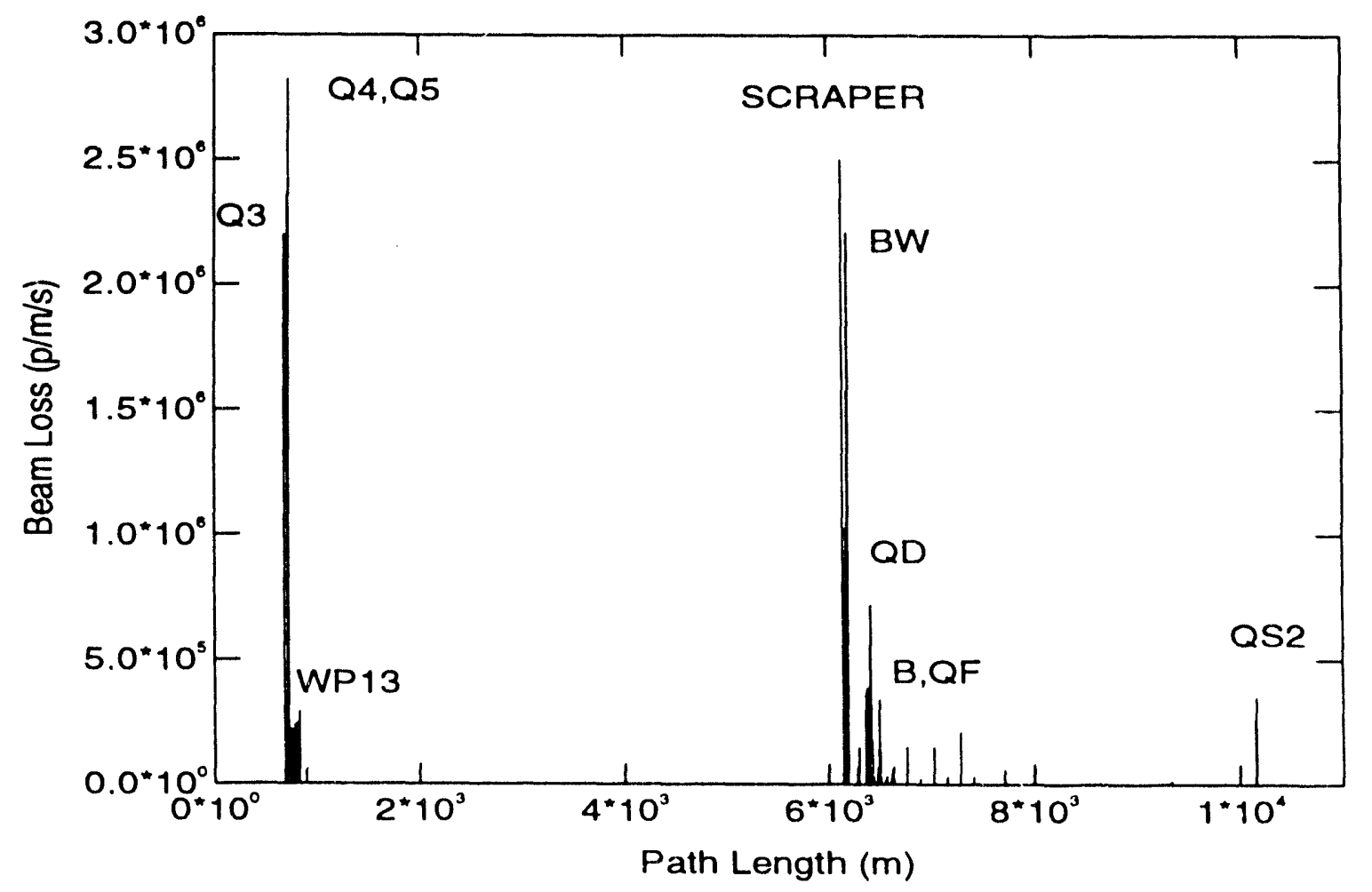

Figure 5. Beam Loss due to Clockwise Scraping without Collimators at South East Stralght Section. 


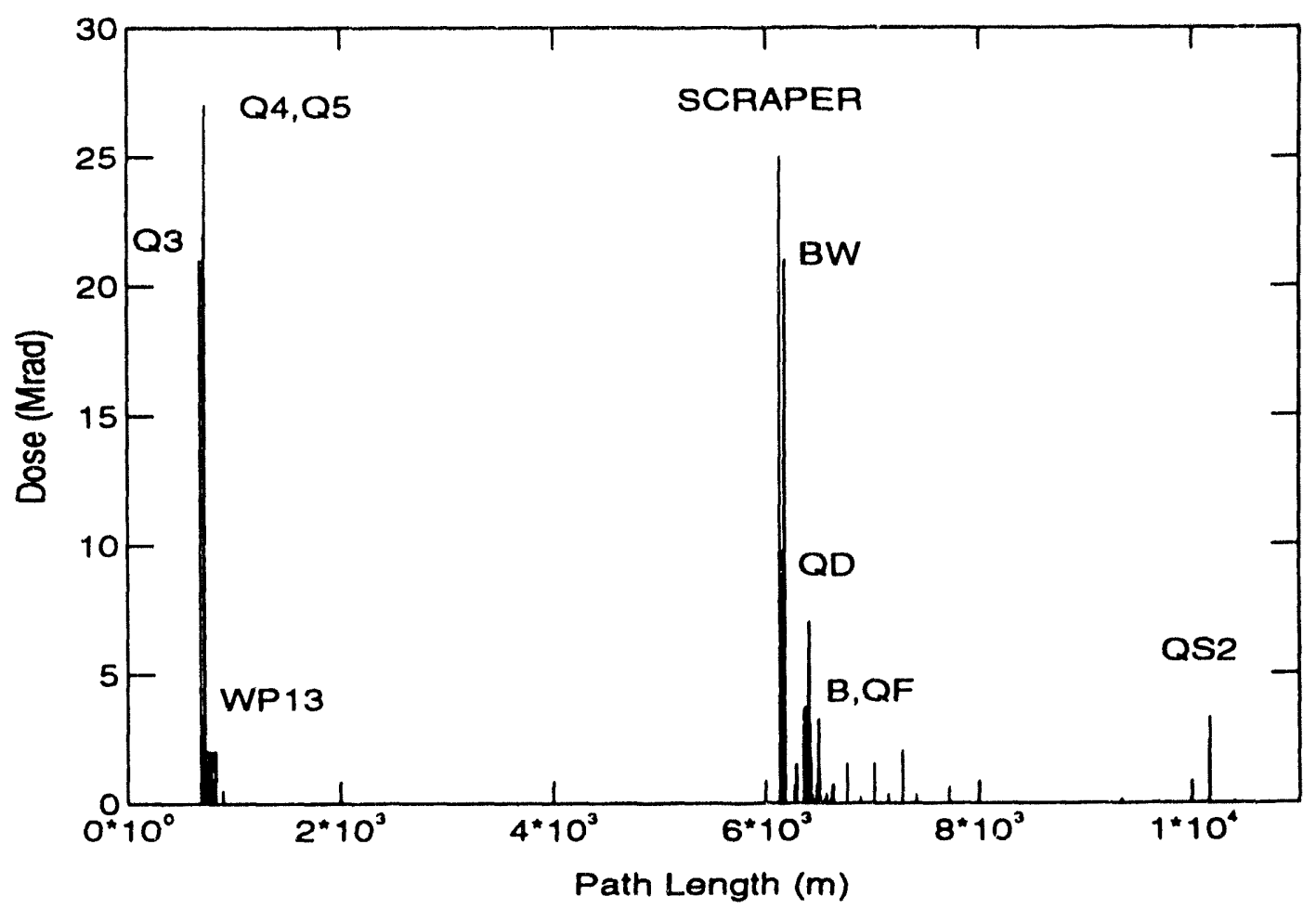

Figure 6. Peak Dose Accumulated over 25 Years In the HEB Magnets without Collimators in South East Straight Soction.

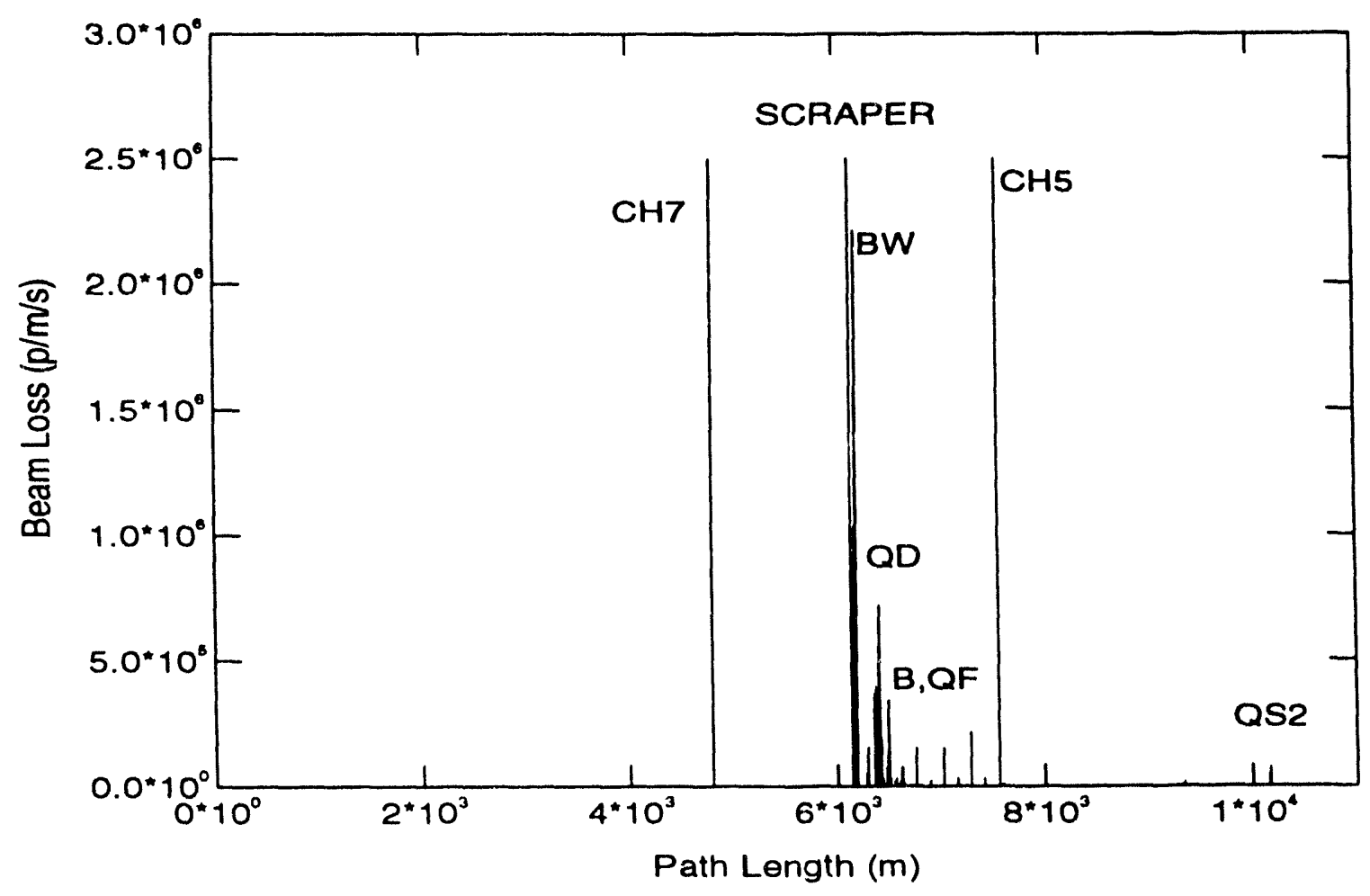

Figure 7. Beam Loss due to Clockwise Scraping with Collimators at South East Straight Section. 


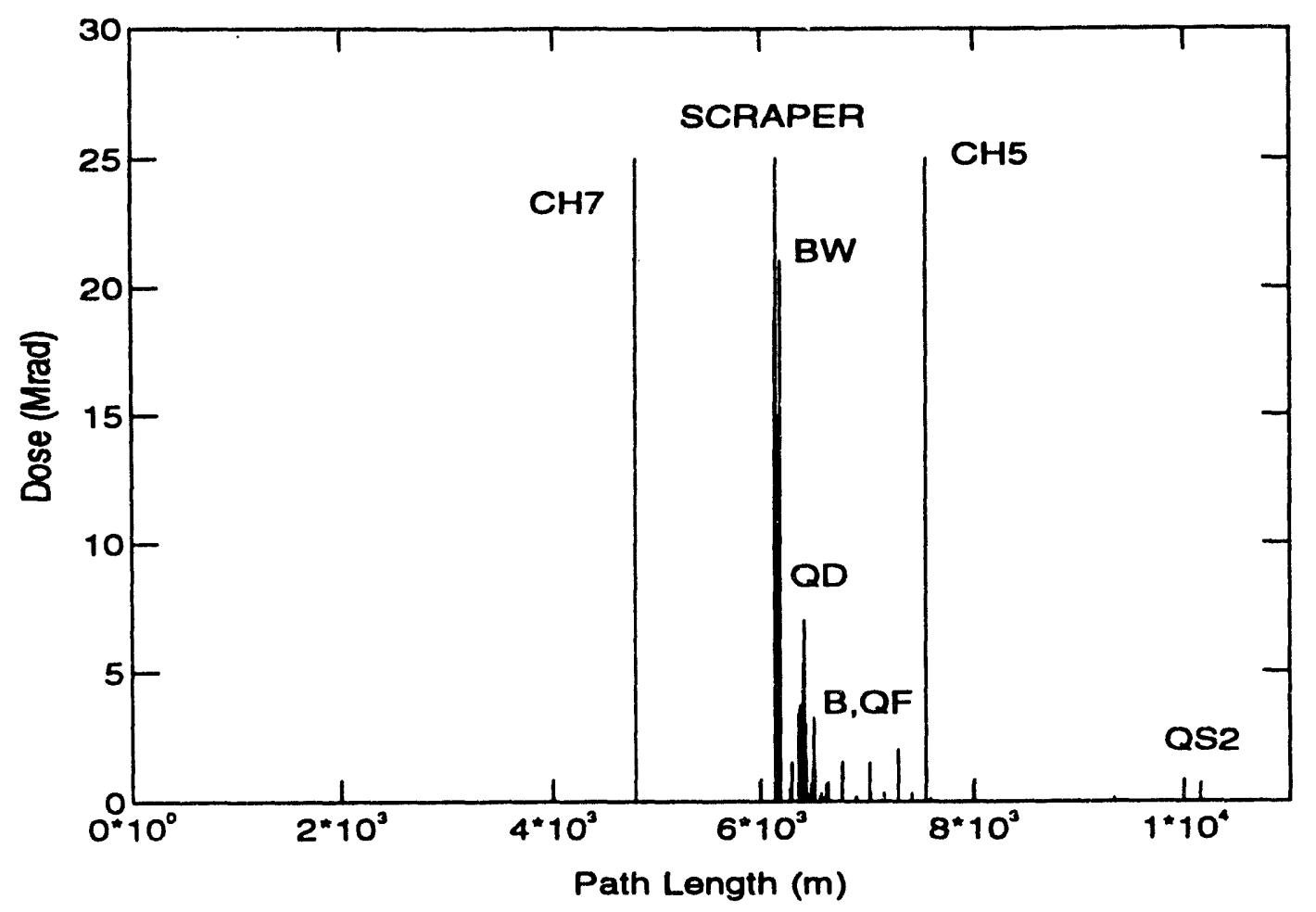

Figure 8. Peak Dose Accumulated over 25 Years in the HEB Magnets with Collimators in South East Straight Section.

\subsection{INJECTION FAILURES, ABORT KICKER PREFIRES AND UNSYNCHRONIZED ABORT}

Figure 9 illustrates the path and $3 \sigma$ profile of the injected beam for the worst case scenario in which all of the HEB injection kickers fail to fire in the expected time window. The circulating HEB beam equivalent to one MEB batch will have the same displacement but in the opposite direction if and when the injection kickers misfire outside the required time window. To protect the machine we propose to put a special collimator. Position for a $1.5-\mathrm{m}$ long graphite horizontal collimator jaws followed by $0.5-\mathrm{m}$ stainless steel jaws is indicated in Figure 9. According to energy deposition calculations, the MEB beam at injection energy to HEB is stopped by this collimator.

The HEB abort system uses fast extraction to divert the beam to a massive graphite absorber at normal termination of the operating cycle or in case of any of a number of predefined fault modes. The abort kicker magnet system for both directions consists of 7 pulsed magnets having a rise time of about $1.7 \mu \mathrm{s}$ (Figure 10). Normally this system is triggered during the $1.7 \mu \mathrm{s}$ abort gap in the circulating beam. If one or more of the kickers prefire or misfire, some fraction of the beam may not reach the absorber. The abort kicker prefire results in a coherent betatron oscillation of the beam with a rather high amplitude. Beam halo particles which are intercepted by the collimators and Lambertson magnets can induce overheating of this equipment to several hundred degrees centigrade. The worst situation takes place at $2 \mathrm{TeV}$ before injection to the Collider. Simulations of this process have been done for the following assumptions. We assumed that the circulating beam has been cleaned to the 100 level by the scraper, and that $99 \%$ of the circulating beam is inside the $4 \sigma$ region and $1 \%$ of the beam is between 4 and $10 \sigma$. All collimators are positioned at $25 \sigma$ with respect to the HEB closed orbit. The admittance of machine is equal to $42 \sigma$ of the circulating beam at top energy. 


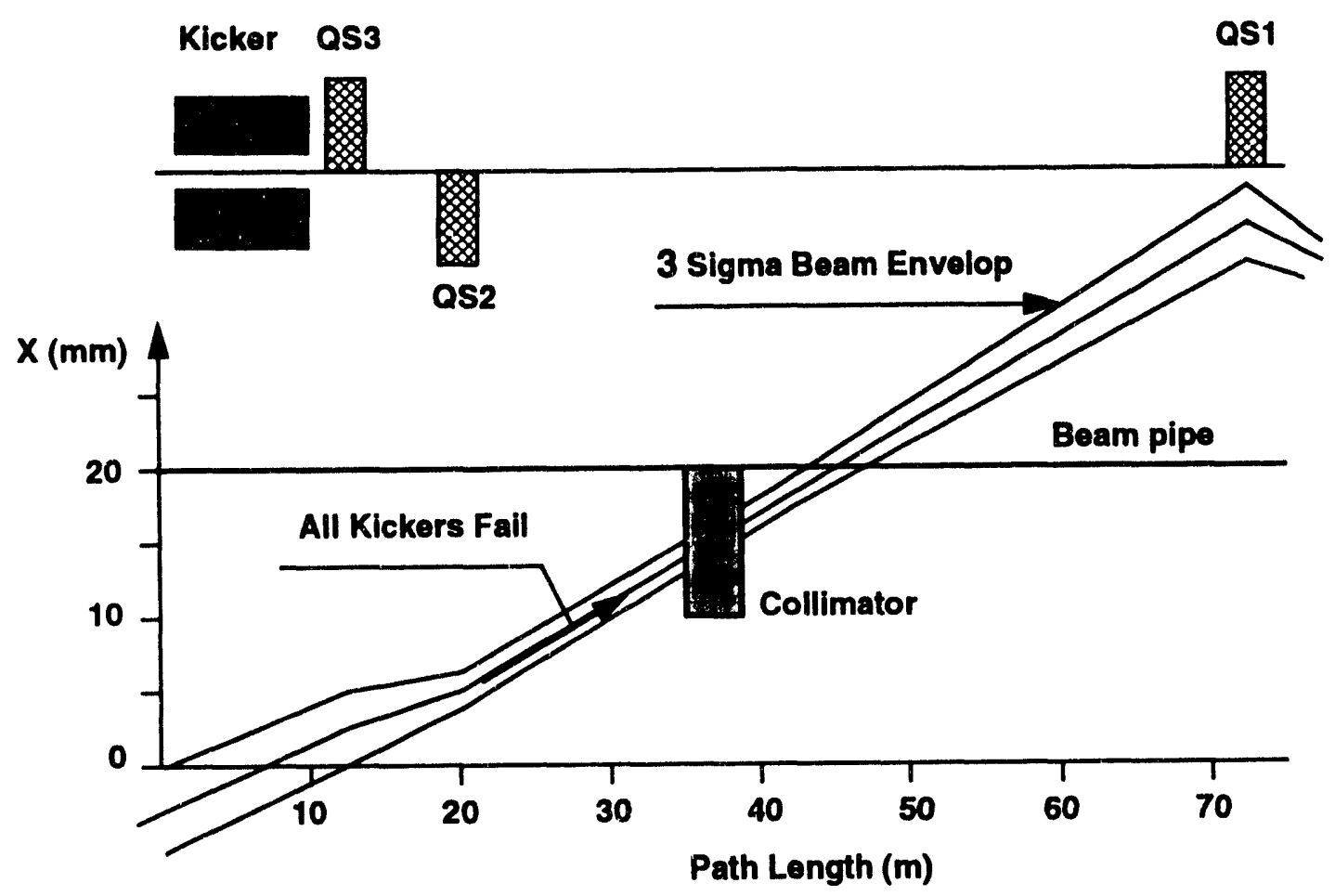

Figure 9. Injected Beam Centrold Position due to Falled Injection Klcker.

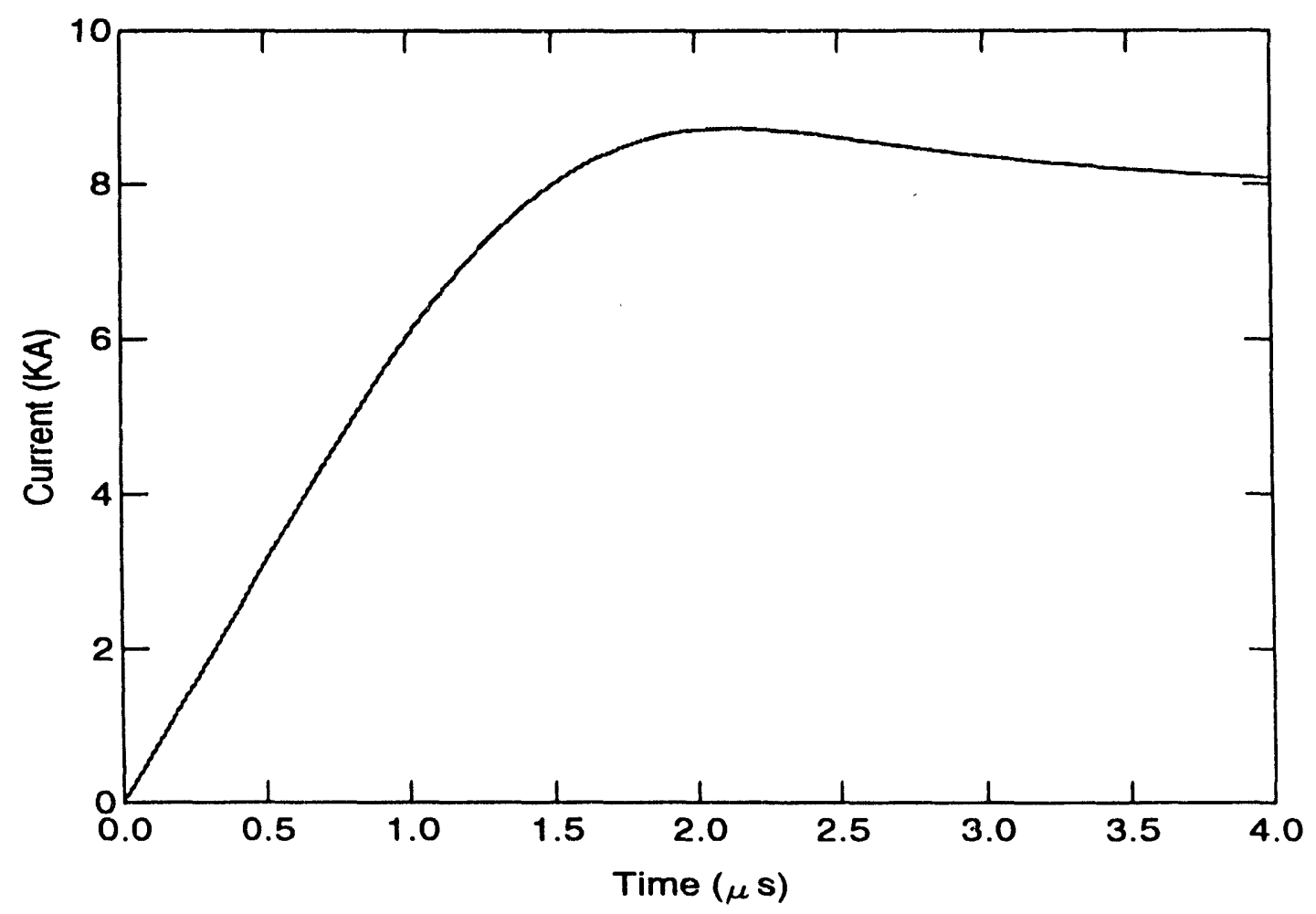

Figure 10. Abort Kicker Pulse Rise Time. 
In a worst case, when prefire of an abort kicker takes place just after the longitudinal abort gap passed the kicker, one needs to wait one turn to abort the beam out of the HEB. The overheating of the collimators CUTV2, CUTV3 in the H50 east long straight section and of the extraction Lambertson for injection of the beam to the Collider in $\mathrm{H} 10$ straight considerably exceeds the melting point of steel. Positions of the beam at these locations of accelerator are shown in Figure 11. To avoid overheating of these devices one should make an unsynchronized abort. Unfortunately the kicker pulse rise time is unlikely to be contained within the abort gap of the circulating beam. Results of a simulation of beam loss during the $1.7 \mu$ s kicker rise time are presented in Figure 12. At the beginning of the kicker pulse, particles are intercepted by a collimators in the H50 straight sections and by quadrupole QS2. The maximum instantaneous temperature rise of collimators is $400^{\circ} \mathrm{C}$, and of quadrupole QS2 $\sim 60^{\circ} \mathrm{C}$.

At $25-60 \%$ level of the kicker strength, the deflected beam is intercepted by the abort Lambertson magnet and shadow downstream Lambertson magnet (Figure 13.). The same applies for counterclockwise direction. Steel shadow is used to protect superconducting magnets downstream against irradiation at unsynchronized abort. Maximum overheating in the Lambertson septum and shadow is equal to $800{ }^{\circ} \mathrm{C}$.

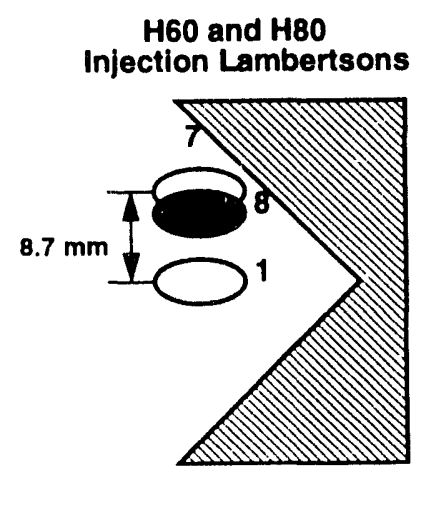

$\mathrm{H} 2 \mathrm{O}$ and $\mathrm{H4O}$ Abort Lambertson

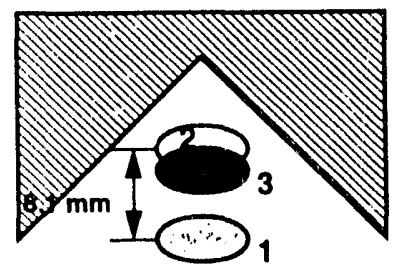

$\mathrm{H} 10 \mathrm{CW}$ and $\mathrm{CCW}$ Extraction Lambertsons

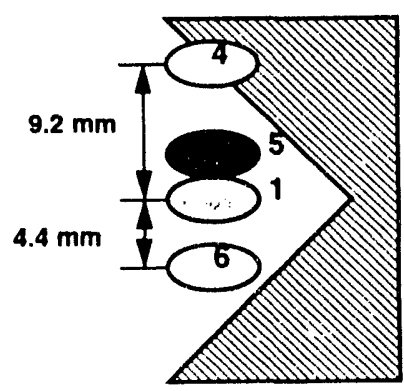

CUTV2, CUTV3

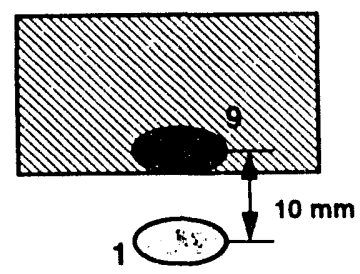

1 - circulating beam

2 - $\mathrm{CW}$ abort prefire in $\mathrm{H} 2 \mathrm{O}$ Lambertson

3 - CW abort prefire in $\mathrm{H} 40$ Lambertson

4. $\mathrm{CW}$ abort prefire in CCW extraction Lambertson

5 - CCW abort prefire in CCW extraction Lambertson

6. $\mathrm{CW}$ abort prefire in $\mathrm{CW}$ extraction Lambertson

7 - CW abort prefire in $\mathbf{H} 60$ Lambertson

8 - CW abort prefire in $\mathrm{H} 80$ Lambertson

9 - CW and CCW abort prefire in CUTV2 and CUTV3

Figure 11. Beam Position in Injection, Extraction and Abort Lambertson Magnets and Collimators at Abort Kicker Prefire. 


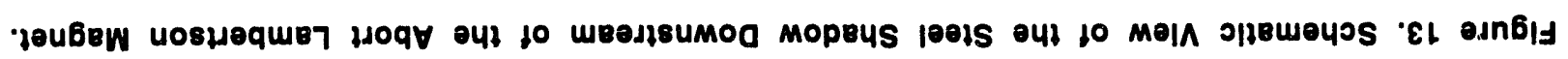
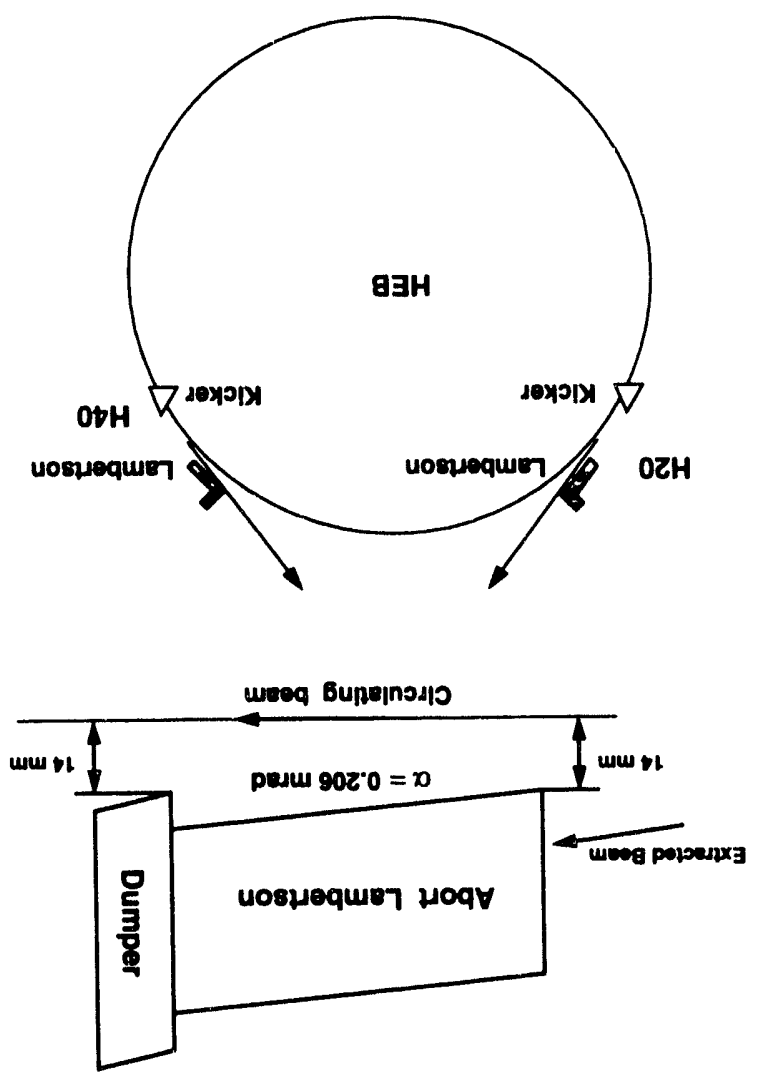

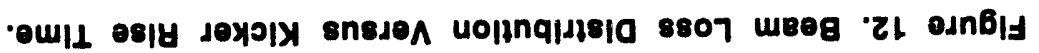

(su) $\theta u ! \perp$

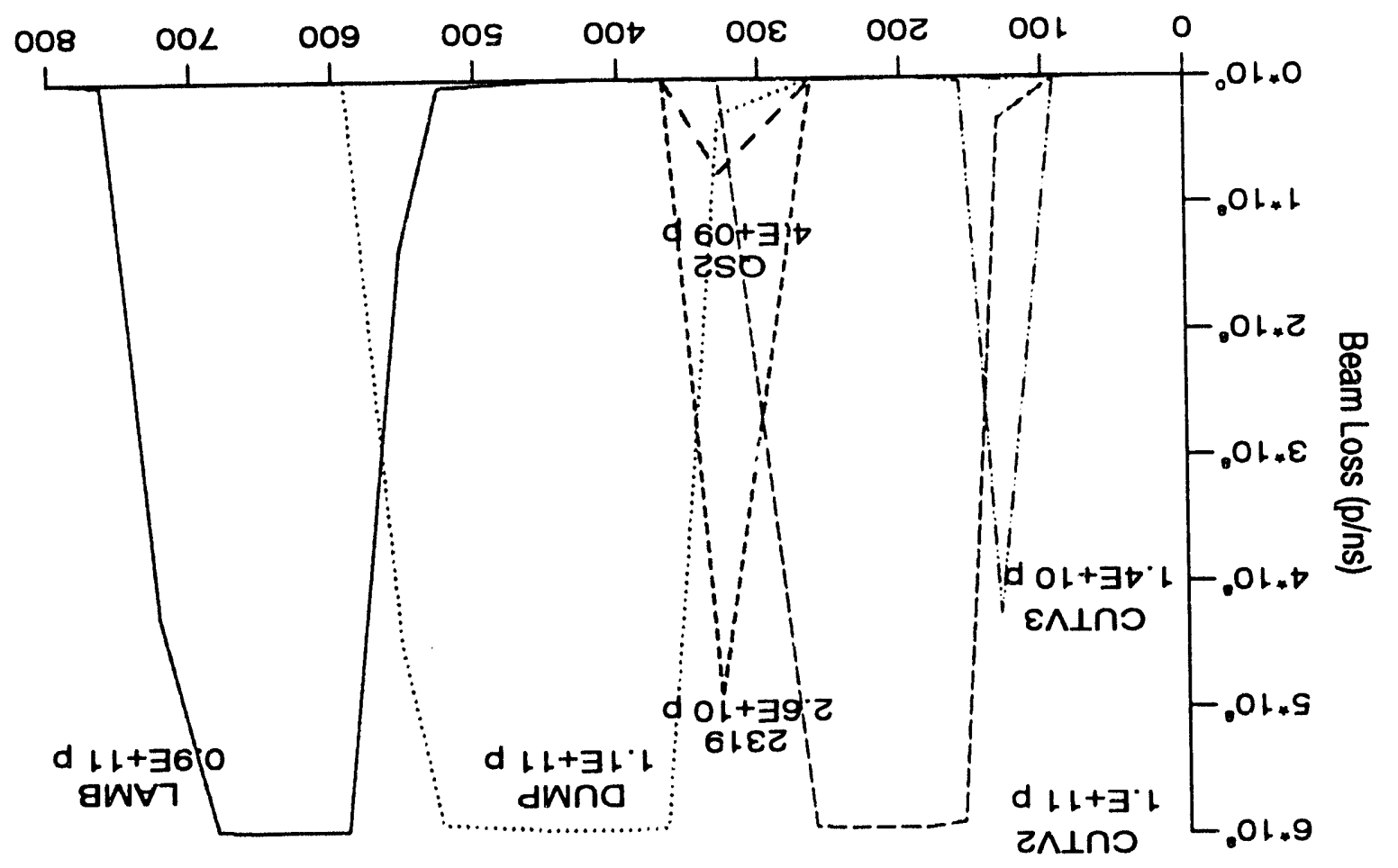




\subsection{CONCLUSIONS}

In conclusion, we believe that such a system of collimation and scraping as described in this report should be implemented as a design requirement in order to achieve reasonable dose rates ( $<200 \mathrm{Mrad}$ ) for all but a few superconducting magnets in the HEB over the 25 year life time of the SSC.

\section{ACKNOWLEDGEMENTS}

The authors wish to thank Gerry Dugan, Victor Yarba and Jay Jayakumar for valuable discussions.

\section{REFERENCES}

1. HEB 3B Specifications, E10-000054, SSCL (1993).

2. N. Mokhov, "MARS12 Code System," Proc. SARE Workshop, Santa Fe (1993); N. Mokhov, "MARS10 Code System User's Guide," Fermilab FN-509.

3. I. Baishev, A. Drozhdin, N. Mokhov, "STRUCT Code User's Reference Manual," SSCL-MAN-0034 (1994).

4. A. Drozhdin, M. Harrison, N. Mokhov, "Study of Beam Losses During Fast Extraction of $800 \mathrm{GeV}$ Protons from the Tevatron," Fermilab FN-418 (1985).

5. M. Maslov, N. Mokhov, I. Yazynin, "The SSC Beam Scraper System," SSCL-484 (1991).

6. A. Drozhdin, N. Mokhov, R. Soundranayagam, J. Tompkins, "Toward Design of the Collider Beam Collimation System," SSCL-PP-555 (1994). 

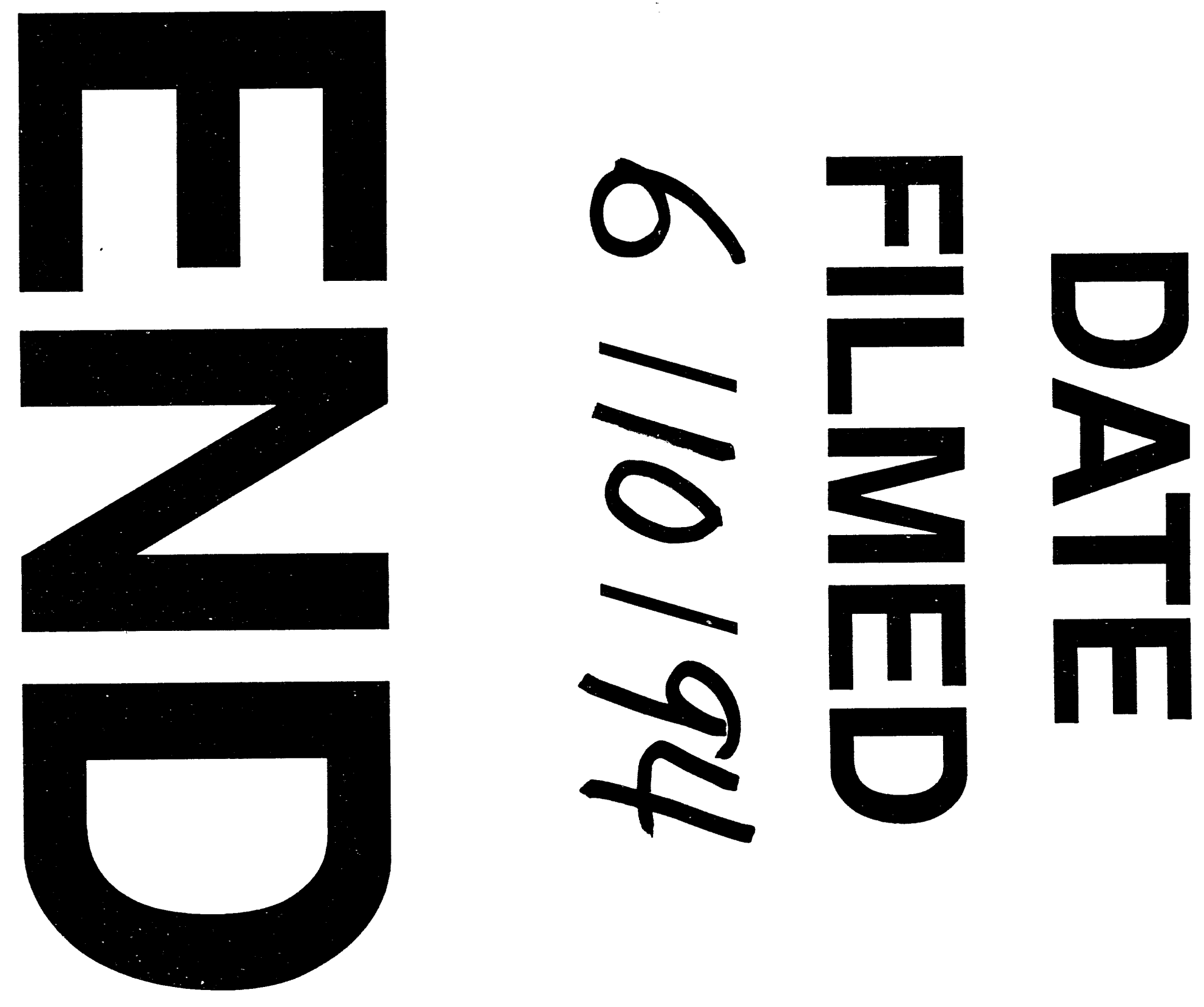
